\title{
EZH2 expression correlates with locoregional recurrence after radiation in inflammatory breast cancer
}

Bisrat G Debeb ${ }^{1,6}$, Yun Gong ${ }^{2,6}$, Rachel L Atkinson ${ }^{3,6}$, Nour Sneige ${ }^{2}$, Lei Huo ${ }^{2,6}$, Ana Maria Gonzalez-Angulo4, Mien-Chie Hung ${ }^{5,8}$, Vicente Valero ${ }^{4,6}$, Naoto T Ueno ${ }^{4,6}$ and Wendy A Woodward ${ }^{1,6,7^{*}}$

\begin{abstract}
Background: Enhancer of zeste homolog 2 (EZH2), a member of the polycomb group proteins, has been shown to promote cancer progression and breast cancer stem cell (CSC) expansion. Breast CSCs are associated with resistance to radiation in inflammatory breast cancer (IBC), a rare but aggressive variant of breast cancer. In this retrospective study, we examined the clinical role of EZH2 in locoregional recurrence (LRR) of IBC patients treated with radiation.

Patients and methods: 62 IBC patients who received radiation (7 pre-operative, 55 post-operative) and had adequate follow up to assess LRR were the subject of this study. Positive EZH2 status was defined as nuclear immunohistochemical staining in at least 10\% of invasive cancer cells. Association of EZH2 expression with clinicopathologic features were evaluated using the Chi-square statistic and actuarial LRR free survival (LRFS) was determined using the Kaplan-Meier method.

Results: The median follow-up for this cohort was 33.7 months, and the 5-year overall LRFS rate was 69\%. Of the 62 patients, 16 (25.8\%) had LRR, and 15 out of 16 LRR occurred in EZH2 expressing cases. Univariate analysis indicated that patients who had EZH2-positive IBC had a significantly lower 5-year locoregional free survival (LRFS) rate than patients who had EZH2-negative IBC (93.3\% vs. 59.1\%; $\mathrm{P}=0.01)$. Positive $\mathrm{EZH} 2$ expression was associated significantly with negative ER status $(97.1 \%$ in ER- vs $48.1 \%$ in $E R+; P<0.0001)$ and triple-negative receptor status $(P=0.0001)$ and all triple-negative tumors were EZH2-positive. In multivariate analysis, only triple negative status remained an independent predictor of worse LRFS (hazard ratio 5.64, 95\% Cl $2.19-14.49, \mathrm{P}<0.0001$ ).
\end{abstract}

Conclusions: $\mathrm{EZH} 2$ correlates with locoregional recurrence in IBC patients who received radiation treatment. EZH2 expression status may be used in addition to receptor status to identify a subset of patients with IBC who recur locally in spite of radiation and may benefit from enrollment in clinical trials testing radiosensitizers.

Keywords: Inflammatory breast cancer, EZH2, Radiation, Locoregional recurrence

\section{Introduction}

The use of ionizing radiation is an integral component of breast cancer treatment for all patients who receive breast conserving surgery and in most patients with locally advanced breast cancer. Resistance to radiation is, however, a common reason for local recurrence in breast cancer patients, especially in breast cancers with high

\footnotetext{
* Correspondence: wwoodward@mdanderson.org

'Department of Radiation Oncology, The University of Texas M. D. Anderson Cancer Center, Houston, TX, USA

${ }^{6}$ Morgan Welch Inflammatory Breast Cancer Research Program and Clinic, The University of Texas M.D. Anderson Cancer Center, Houston, TX, USA Full list of author information is available at the end of the article
}

risk of recurrence such as inflammatory and triplenegative breast cancers $[1,2]$. Recurrence is thought to be driven in part by tumor initiating cells or cancer stem cells (CSCs), a subpopulation of self-renewing cancer cells which exhibit tumor initiating properties and have been shown to contribute to the development of resistance to radiation and chemotherapy. Our lab and others have provided evidence that breast CSCs are resistant to radiation [3-5] although detailed mechanisms of resistance have yet to be fully investigated.

Inflammatory breast cancer (IBC) is a rare but aggressive variant of invasive breast cancer characterized by 
rapid progression, enlargement of the breast, skin edema and erythema. Typically, IBC is associated with rapid metastasis, resistance to treatment, and poor prognosis-all hallmarks of the CSC hypothesis. To date clinical and preclinical data strongly correlate CSCs with IBC [6]. Despite advances in multimodal breast cancer care, the clinical outcome of these patients remains poor demonstrating a critical need to identify novel therapeutics that target the distinct biology of IBC. A recent study by Gong and colleagues [7] showed that Enhancer of zeste homolog 2 (EZH2), a member of the polycomb group proteins, is expressed very frequently in IBC and is associated with worse clinical outcome in these patients. This work was supported by in vitro findings that EZH2 is expressed at higher levels in human IBC cell lines and its knockdown suppresses growth and invasion in IBC cells [8]. Previous studies have shown that EZH2 is involved in maintaining the self-renewal capability of adult and embryonic stem cells $[9,10]$ and recently, Chang et al has demonstrated that EZH2 promotes the expansion of breast CSCs and that it impairs DNA repair in breast cancer cells by specific downregulation of RAD51 gene [11]. In addition, they showed that HIF1 $\alpha$, a known mediator of radiation resistance, transactivated the EZH2 gene and increased EZH2 expression under hypoxic conditions [11]. These findings suggest a possible involvement of EZH2 in radioresistance, however, the clinical role of EZH2 in local failure and radiation resistance in breast cancer patients is unknown. Herein, we investigated the relation between EZH2 expression and locoregional failure and found that positive EZH2 expression correlates with lower locoregional recurrence free survival after radiation in IBC patients.

\section{Materials and methods}

This study was approved by The University of Texas MD Anderson Cancer Center Institutional Review Board. The diagnosis, preoperative and postoperative treatments of these patients, biomarker study (encompassing ER, PR, and HER2 status), and tissue microarray (TMA) construction using post-neoadjuvant residual tumors as well as EZH2 immunohistochemical staining and evaluation were previously reported [7]. EZH2 staining was interpreted and recorded independently by 2 pathologists (Y.G. and L.H.) in a blinded manner. Positive EZH2 status was defined as nuclear staining in at least $10 \%$ of invasive cancer cells. Images of negative and positive EZH2 staining results in representative tumors are shown in Figure 1. To evaluate the role of EZH2 in radiation resistance, the radiation record of all patients was re-reviewed and only patients who received radiation (62 patients) were included in this study. Patients who had local failure prior to receiving radiation were excluded from this analysis.

\section{Statistical analysis}

Chi-square or Fisher exact test was used to evaluate associations between EZH2 status and clinicopathologic variables. We used the Kaplan-Meier method to estimate actuarial LRR free survival (LRFS). LRFS was calculated from the date of initial pathologic diagnosis of the primary tumor to the date of locoregional recurrence or the date of last follow-up and any locoregional recurrence was considered an event. A Cox proportional hazards regression model was then used to test the statistical significance of several potential prognostic factors for LRFS. The factors analyzed included EZH2 expression; age; race; lymph node status; histologic type; lymphovascular invasion; ER, PR, and HER-2 status; triple-negative (ERnegative, PR-negative, and HER2 negative) status; and twice-a-day (BID) radiation. This modeling was done in a univariate fashion. Then, all potential prognostic factors with a $\mathrm{P}$ value $<.25$ from the univariate analysis were included in a saturated model, and backward elimination was used to remove factors from the model based

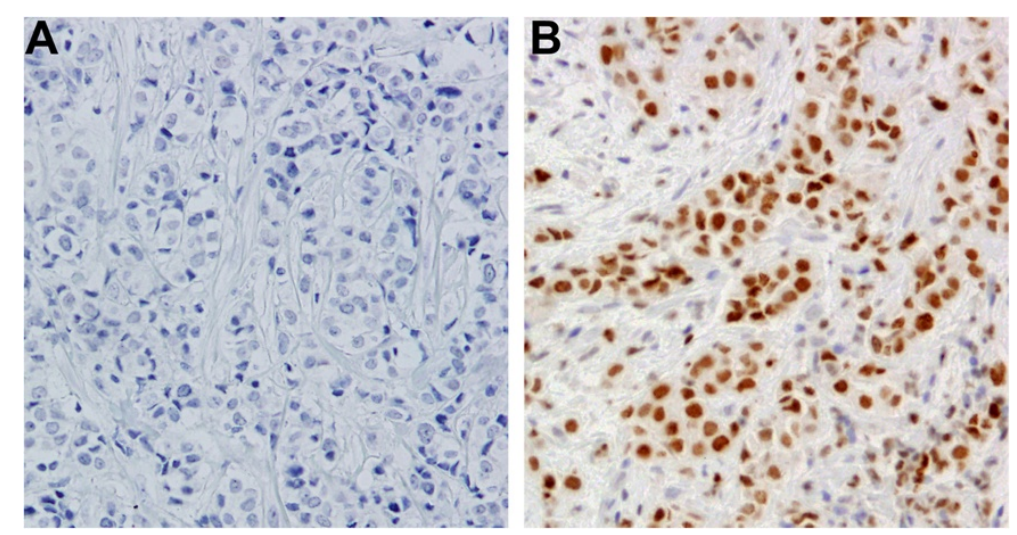

Figure 1 Representative images for immunohistochemical staining of EZH2 in IBC tumors (A) EZH2-negative IBC tumor (B) EZH2-positive IBC tumor. 
on the likelihood ratio test in the multiple regression analysis. All statistical analysis was conducted using StataCorp. 2011. Stata Statistical Software: Release 12. College Station, TX: StataCorp LP. All reported P values were 2sided, and $\mathrm{P}<0.05$ was considered statistically significant.

\section{Results}

The cohort of IBC patients used in this study and the EZH2 expression were described previously [7]. Briefly, tumors from 88 patients with primary IBC were included of which EZH2 staining was available for 74 tumors. Patients received multimodal treatment, including neoadjuvant chemotherapy, surgery, and radiation therapy. At the completion of neoadjuvant chemotherapy, all patients underwent mastectomy; most patients also underwent axillary lymph node dissection. Thirty-one patients received adjuvant endocrine therapy, and all patients with HER2-positive tumors received adjuvant trastuzumab.

Table 1 Comparison of clinicopathological parameters in women who received radiation stratified by EZH2 expression

\begin{tabular}{|c|c|c|c|c|c|}
\hline \multirow[t]{2}{*}{ Prognostic factors } & \multicolumn{2}{|l|}{ EZH2 negative } & \multicolumn{2}{|l|}{ EZH2 positive } & \multirow[b]{2}{*}{$P$ value } \\
\hline & Number of patients & Percent & Number of patients & Percent & \\
\hline \multicolumn{6}{|l|}{ Age of diagnosis $(\mathrm{N}=62)$} \\
\hline$\geq 45$ & 11 & 68.75 & 29 & 63.04 & \multirow[t]{2}{*}{0.77} \\
\hline$<45$ & 5 & 31.25 & 17 & 39.96 & \\
\hline \multicolumn{6}{|l|}{ Race $(\mathrm{N}=59)$} \\
\hline Non-Hispanic White & 15 & 93.75 & 33 & 76.74 & \multirow[t]{2}{*}{0.26} \\
\hline All others & 1 & 6.25 & 10 & 23.26 & \\
\hline \multicolumn{6}{|c|}{ Lymph node status $(N=60)$} \\
\hline Negative & 3 & 18.75 & 4 & 9.09 & \multirow[t]{2}{*}{0.23} \\
\hline Positive & 13 & 81.25 & 40 & 90.91 & \\
\hline \multicolumn{6}{|l|}{ Histologic type $(\mathrm{N}=62)$} \\
\hline Ductal & 12 & 75.0 & 42 & 91.30 & \multirow[t]{2}{*}{0.19} \\
\hline Others & 4 & 25.0 & 4 & 8.70 & \\
\hline \multicolumn{6}{|c|}{ Lymphovascular invasion $(\mathrm{N}=56)$} \\
\hline No & 4 & 26.67 & 5 & 12.20 & \multirow[t]{2}{*}{0.23} \\
\hline Yes & 11 & 73.33 & 36 & 87.80 & \\
\hline \multicolumn{6}{|l|}{ ER expression $(\mathrm{N}=61)$} \\
\hline Negative & 1 & 6.67 & 33 & 71.74 & \multirow[t]{2}{*}{$<0.0001$} \\
\hline Positive & 14 & 93.33 & 13 & 28.26 & \\
\hline \multicolumn{6}{|l|}{ PR expression $(N=61)$} \\
\hline Negative & 8 & 53.33 & 34 & 73.91 & \multirow[t]{2}{*}{0.19} \\
\hline Positive & 7 & 46.67 & 12 & 26.09 & \\
\hline \multicolumn{6}{|l|}{ HER2 expression $(\mathrm{N}=61)$} \\
\hline Negative & 11 & 73.33 & 28 & 60.87 & \multirow[t]{2}{*}{0.54} \\
\hline Positive & 4 & 26.67 & 18 & 39.13 & \\
\hline \multicolumn{6}{|c|}{ Triple-negative status $(\mathrm{N}=61)$} \\
\hline No & 15 & 100.00 & 30 & 65.22 & \multirow[t]{2}{*}{0.005} \\
\hline Yes & 0 & 0.00 & 16 & 34.78 & \\
\hline \multicolumn{6}{|l|}{ Radiation type $(\mathrm{N}=62)$} \\
\hline Preoperative & 1 & 6.25 & 6 & 13.04 & \multirow[t]{2}{*}{0.66} \\
\hline Postoperative & 15 & 93.75 & 40 & 86.96 & \\
\hline \multicolumn{6}{|l|}{ BID radiation $(\mathrm{N}=48)$} \\
\hline No & 0 & 0.00 & 10 & 26.32 & \multirow[t]{2}{*}{0.09} \\
\hline Yes & 10 & 100.00 & 28 & 73.68 & \\
\hline \multirow[t]{2}{*}{ Radiation dose $(\mathrm{N}=48)$} & & Dose & & Dose & \\
\hline & 11 & 67.09 & 37 & 63.47 & 0.03 \\
\hline
\end{tabular}


Timing of radiation was explicitly reviewed for this study. Seven patients previously classified as post-op radiation [7] were noted to have had pre-operative radiation. In total, sixty-two patients received radiation (7 pre-operative, 55 post-operative) to the chest wall and draining lymphatics. In this study, we reviewed the radiation record of these patients to evaluate the role that $\mathrm{EZH} 2$ plays in mediating radiation resistance in clinically radioresistant IBC.

In the 62 patients who received radiation, the median follow-up was 33.7 months (range, 1.1-181.5 months). The age at the time of initial diagnosis ranged from 23 years to 75 years (median age, 48 years). Forty-eight (81.3\%) were whites, 8 (13.5\%) were Hispanics, and 3 (5.1\%) were Blacks and Asians. Lymph node involvement was observed in 53 of 60 patients (88.3\%). Histologically, 54 of 62 tumors (87.1\%) were ductal type, and 47 of 56 (83.9\%) demonstrated lymphovascular invasion. Positive ER expression was observed in 27 of 61 of tumors (44.2\%), positive PR status was observed in 19 of 61 tumors (31.1\%), and HER2 overexpression and/or amplification was observed in 22 of 61 tumors $(36.1 \%)$. Triple-negative status was observed in 16 of 61 tumors (26.2\%). Thirty-eight of 48 (79.2\%) IBC patients received BID radiation, of which 37 (77.1\%) received a total dose of $63.47 \mathrm{~Gy}$ and the remaining received a dose of $67.09 \mathrm{~Gy}$.

\section{EZH2 expression and clinicopathologic variables in patients who received radiation}

In this cohort positive EZH2 expression was associated significantly with negative ER status $(\mathrm{P}<0.0001)$ and triplenegative status $(\mathrm{P}=0.005)$. Specifically EZH2 was expressed more frequently in ER-negative (97.1\%; 33 of 34 ER- tumors) than ER-positive patients (48.1\%; 13 of $27 \mathrm{ER}+$ tumors) treated with radiation (Table 1). All triple-negative tumors were EZH2-positive. EZH2 expression was not associated significantly with lymphnode status, histologic type, lymphovascular invasion, PR status, HER2 status and BID radiation (Table 1). Similar results were found when only post mastectomy radiation-treated IBC patients were analyzed (data not shown).

\section{EZH2 expression and local failure}

Of the 62 patients who had follow-up information available on LRR, the median LRFS duration was 4.04 years (95\% CI, 2.85-8.79 years). The 5-year LRFS rate for the entire cohort of patients was 69\% (Figure 2). Sixteen (25.8\%) had LRR and notably 15 of the 16 LRR occurred in $\mathrm{EZH} 2$ positive patients. In univariate analysis, positive EZH2 expression was associated significantly with a lower LRFS rate $(\mathrm{P}=0.01)$ (Figure 2$)$. The 5 -year LRFS rate for patients who had EZH2-positive tumors was $59.1 \%$ compared with $93.3 \%$ for patients who had EZH2negative tumors (Figure 2A). Among the 55 patients who had post mastectomy radiation, positive EZH2 expression was also significantly associated with lower LRFS rates (5-year LRFS EZH2-positive $=59.4 \%$, EZH2negative $=92.9 \%, \mathrm{P}=0.01$; Figure $2 \mathrm{~B}$ ).

Univariate analyses were performed to determine whether any other clinicopathologic factors were associated with the clinical outcome of IBC patients. We observed that lower LRFS rates were associated significantly with negative ER status $(\mathrm{P}=0.001)$ and with triplenegative status (Table $2 ; \mathrm{P}=0.0001$ ). There was no significant association between LRFS rates and histologic type, age, race, lymph node status, and HER2 status while there was a trend with lymphovascular invasion $(\mathrm{P}=0.07)$. In multivariate analysis, we observed that only triple negative status remained an independent predictor of LRFS (hazard ratio 5.64, 95\% CI $2.19-14.49, \mathrm{P}<0.0001$; Table 3$)$. We reasoned that failure of EZH2 to predict local recurrence was influenced by triple negative-receptor-status since all of the triple-negative tumors were EZH2-positive. Thus, we excluded triple negative tumors from the analysis and we found that EZH2 has a trend to be an independent predictor of worst LRFS in the 45 IBC patients analyzed (6.57, 95\% CI 0.82-52.87; P = 0.08) (Table 4).
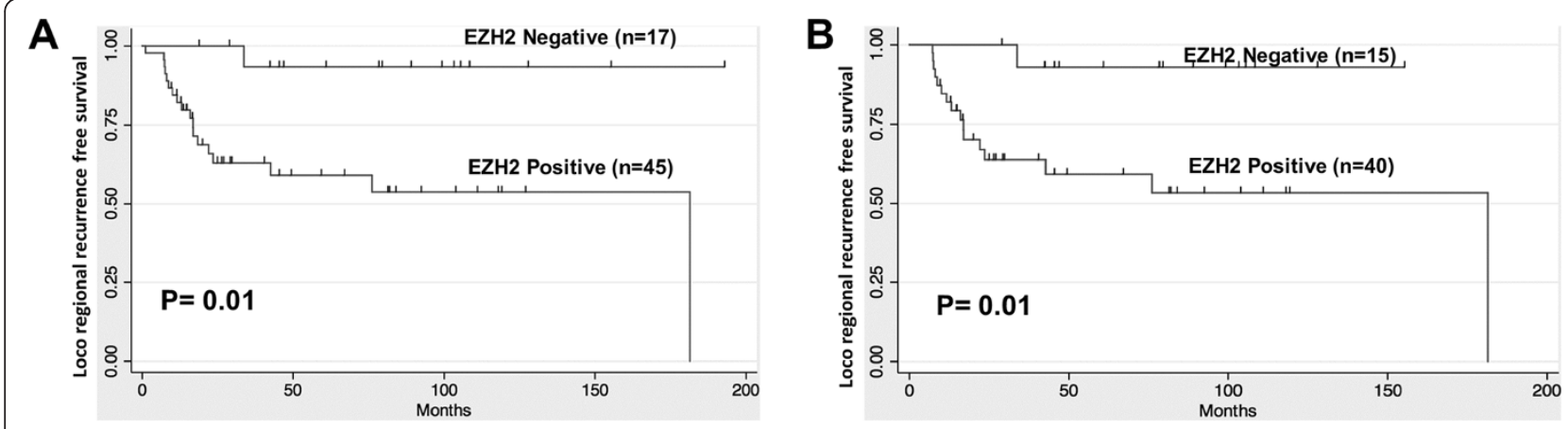

Figure 2 Kaplan Meier curve showing that EZH2 is associated with lower LRFS in IBC patients. A) All patients who received pre- and post-operative radiation treatment $(N=62)$ and $\mathbf{B})$ Postmastectomy radiation cohort $(N=55)$ showed that the LRFS in EZH2 negative cases was significantly higher than in EZH2-positive cases $(P=0.01)$. 
Table 2 Relation between LRFS, EZH2 and clinicopathologic factors in patients who received radiation

\begin{tabular}{|c|c|c|c|}
\hline Prognostic factors & Number of patients/number of deaths & 5-year LRFS $(95 \% \mathrm{Cl})$ & $P$ value \\
\hline \multicolumn{4}{|l|}{ Age of diagnosis $(\mathrm{N}=62)$} \\
\hline$\geq 45$ & $40 / 12$ & $72.7(54.8-84.8)$ & \multirow[t]{2}{*}{0.43} \\
\hline$<45$ & $22 / 7$ & $60.9(33.9-79.6)$ & \\
\hline \multicolumn{4}{|l|}{ Race $(\mathrm{N}=59)$} \\
\hline Non-Hispanic White & $48 / 13$ & $74.3(58.4-85.1)$ & \multirow[t]{2}{*}{0.36} \\
\hline All others & $11 / 4$ & $56.1(19.5-81.5)$ & \\
\hline \multicolumn{4}{|c|}{ Lymph node status $(\mathrm{N}=60)$} \\
\hline Negative & $7 / 2$ & $83.3(27.3-97.4)$ & \multirow[t]{2}{*}{0.79} \\
\hline Positive & $53 / 16$ & $67.3(51.3-79.2)$ & \\
\hline \multicolumn{4}{|l|}{ Histologic type $(N=62)$} \\
\hline Ductal & $54 / 17$ & $68.7(53.2-80.1)$ & \multirow[t]{2}{*}{0.72} \\
\hline Others & $8 / 2$ & $75.0(31.5-93.1)$ & \\
\hline \multicolumn{4}{|c|}{ Lymphovascular invasion ( $N=56)$} \\
\hline No & $9 / 0$ & 100 & \multirow[t]{2}{*}{0.07} \\
\hline Yes & $47 / 16$ & $66.8(48.9-78.5)$ & \\
\hline \multicolumn{4}{|l|}{ ER expression $(\mathrm{N}=61)$} \\
\hline Negative & $34 / 16$ & $44.4(24.1-62.9)$ & \multirow[t]{2}{*}{0.001} \\
\hline Positive & $27 / 3$ & $92.3(72.6-98.0)$ & \\
\hline \multicolumn{4}{|l|}{ PR expression $(\mathrm{N}=61)$} \\
\hline Negative & $42 / 16$ & $58.4(39.9-73.0)$ & \multirow[t]{2}{*}{0.025} \\
\hline Positive & $19 / 3$ & $88.2(60.2-96.9)$ & \\
\hline \multicolumn{4}{|l|}{ HER2 expression $(\mathrm{N}=61)$} \\
\hline Negative & $39 / 13$ & $68.5(49.9-81.2)$ & \multirow[t]{2}{*}{0.81} \\
\hline Positive & $22 / 6$ & $70.0(39.1-84.3)$ & \\
\hline \multicolumn{4}{|c|}{ Triple-negative status $(\mathrm{N}=61)$} \\
\hline No & $45 / 9$ & $82.6(66.6-91.4)$ & \multirow[t]{2}{*}{0.0001} \\
\hline Yes & $16 / 10$ & $25.7(6.4-51.0)$ & \\
\hline \multicolumn{4}{|l|}{ Radiation type $(\mathrm{N}=62)$} \\
\hline Postoperative & $55 / 17$ & $69.4(54.0-80.5)$ & \multirow[t]{2}{*}{0.73} \\
\hline Preoperative & $7 / 2$ & $64.3(15.2-90.2)$ & \\
\hline \multicolumn{4}{|l|}{ BID radiation $(\mathrm{N}=48)$} \\
\hline No & $10 / 3$ & $80.0(40.9-94.6)$ & \multirow[t]{2}{*}{0.21} \\
\hline Yes & $38 / 14$ & $58.0(38.9-73.0)$ & \\
\hline \multicolumn{4}{|l|}{$\mathrm{EZH} 2(\mathrm{~N}=62)$} \\
\hline No & $17 / 1$ & $92.8(59.1-98.9)$ & \multirow[t]{2}{*}{0.01} \\
\hline Yes & $45 / 18$ & $59.2(41.5-73.1)$ & \\
\hline
\end{tabular}

\section{Discussion}

Herein, we report that EZH2 expression correlates with locoregional recurrence in IBC patients who received radiation. Although EZH2 is associated with local failure after radiation in univariate analyses, it is not independently associated with local failure, in part because nearly all patients with ER-negative disease overexpress EZH2, making it impossible to separate the influences of EZH2 expression and receptor negativity. When examining the influence in non-triple negative cohort, however, EZH2 expression trends to be an independent predictor of locoregional recurrence. As such EZH2 ER + patients may be appropriately included in studies of radiosensitizers for high risk IBC.

The clinical-pathological features of IBC include enrichment of factors that have been previously associated with radioresistant disease, including negative receptor status and a phenotype enriched for radioresistant breast 
Table 3 Multivariate Cox model for LRFS in patients who received radiation

\begin{tabular}{lll}
\hline & Hazard ratio $\mathbf{( 9 5 \% ~ C l )}$ & P value \\
\hline Triple negative status & $5.64(2.19-14.49)$ & $<0.0001$ \\
\hline
\end{tabular}

CSCs $[6,12,13]$. IBC is known to be associated with a high incidence of locoregional recurrence [12,14], and thus, identification of markers and a greater understanding of the biology of radiation resistance in IBC will be desirable in order to develop novel radiosensitizers that could improve local control in IBC patients. The clinical role of $\mathrm{EZH} 2$ in radiation resistance has not been reported before. However, several studies have suggested the possible involvement of EZH2 in radiation resistance. Recent evidence from Hung's group suggests that enhanced expression of EZH2 promotes breast CSC expansion through impairment of the DNA damage repair protein Rad51 and the activation of RAF1-ERK- $\beta$-catenin signaling [11]. They showed that EZH2-mediated downregulation of DNA damage repair leads to accumulation of recurrent $R A F 1$ gene amplification in breast CSCs, which activates $\mathrm{p}$-ERK- $\beta$-catenin signaling to promote CSC expansion. They further revealed that targeting EZH2 downstream activation pathways such as RAF1-ERK signaling with the MEK inhibitor AZD6244 could prevent breast cancer progression by eliminating CSCs. They further showed that HIF1 $\alpha$, a known mediator of radioresistance in breast cancer, activates the $E Z H 2$ gene and increases EZH2 expression under hypoxic conditions [11]. Other studies have also supported the possible role for $\mathrm{EZH} 2$ in modulating radiation response. Dong et al demonstrated that overexpression of Bmi-1, another PcG protein similar to EZH2, elicits radioprotective effects in keratinocytes by mitigating the genotoxic effects of radiation through epigenetic mechanisms [15]. In another study, pharmacologic inhibition of EZH2 induced radiation sensitivity in atypical teratoid/ rhabdoid tumors in vitro [16], and silencing EZH2 with RNAi enhanced radiation sensitivity in lung cancer cells [17]. Collectively, these data together with our current findings that EZH2 is associated with local failure in IBC patients support the hypothesis that EZH2 has a significant role in promoting resistance to radiation treatment. However, it remains unknown which, if any, of the known mechanisms of EZH2 activity actually modulates resistance to radiation therapy.

Table 4 Multivariate Cox model for LRFS in patients who received radiation but excluding those with triple negative receptor status

\begin{tabular}{lll}
\hline & Hazard ratio $(\mathbf{9 5} \% \mathrm{Cl})$ & P value \\
\hline $\mathrm{EZH} 2$ & $6.5(0.82-52.75)$ & 0.077 \\
\hline
\end{tabular}

We and others have provided evidence that breast CSCs are resistant to radiation through upregulation of stem cell self renewal pathways including $\beta$-catenin and Notch signaling $[3,4]$ and other studies have shown that CSCs contribute to radioresistance by preferential activation of the DNA damage checkpoint response and increased DNA repair capacity and by maintaining low ROS levels $[18,19]$. EZH2 has been shown to promote CSC expansion and maintenance $[11,20]$ and to impair DNA repair via downregulation of $\operatorname{Rad} 51$ [11,21]. These findings seem paradoxical given that downregulation of Rad51 is expected to increase radiosensitivity but CSC expansion has been linked with radiation resistance. Further studies are warranted to elucidate this paradox by examining how EZH2 activates radiation resistance mechanisms in breast cancer cells.

It is to be noted that the tumors included in this study comprised tissues from refractory or residual tumors after neoadjuvant systemic therapy. Previous studies have shown that neoadjuvant chemotherapy increased the CSC subpopulation [22] and that EZH2 promotes the expansion of CSCs $[11,20]$. It is possible then that the expression of EZH2 described in this cohort is influenced by neoadjuvant chemotherapy. This should be considered in future studies.

\section{Conclusion}

In conclusion, this retrospective study showed that EZH2 is associated with receptor-negative status and lower locoregional-recurrence free survival rates in IBC patients. Additional examination of the mechanism of this clinical finding and its association with triple negative receptor status is warranted. These findings indicate that EZH2 expression status may be used in conjunction with ER + status to identify a subset of patients with IBC who recur locally in spite of radiation and may benefit from enrollment in clinical trials testing radiosensitizers. Given the high frequency of expression of EZH2 and local recurrence in IBC patients, targeting EZH2 may provide a novel therapeutic strategy to improve local failure of patients with IBC.

\section{Competing interests}

The authors have no competing interests to disclose.

\section{Authors' contributions}

Collection and/or assembly of data: BGD, YG, RLA, WAW; provided and/or characterized patient tissue samples: YG, LH, NS, AMG, MH, W, NTU, WAW; data analysis and interpretation: BGD, YG, RLA, LH, WAW; Manuscript writing: $B G D, Y G$, and WAW; Final approval of manuscript by all authors.

\section{Acknowledgements}

This work was supported by the State of Texas Grant for Rare and Aggressive Breast Cancer Research Program, the National Institutes of Health R01CA13823901 and Susan G. Komen Postdoctoral Fellowship Award (KG101478). 


\section{Author details}

'Department of Radiation Oncology, The University of Texas M. D. Anderson Cancer Center, Houston, TX, USA. ²Department of Pathology, The University of Texas M. D. Anderson Cancer Center, Houston, TX, USA. ${ }^{3}$ Department of Clinical Cancer Prevention, The University of Texas M. D. Anderson Cancer Center, Houston, TX, USA. ${ }^{4}$ Department of Breast Medical Oncology, The University of Texas M. D. Anderson Cancer Center, Houston, TX, USA. ${ }^{5}$ Department of Molecular and Cellular Oncology, The University of Texas M. D. Anderson Cancer Center, Houston, TX, USA. ${ }^{6}$ Morgan Welch Inflammatory Breast Cancer Research Program and Clinic, The University of Texas M.D. Anderson Cancer Center, Houston, TX, USA. ${ }^{7}$ Division of Radiation Oncology, The University of Texas M.D. Anderson Cancer Center, 1515 Holcombe Blvd., Unit 1202, 77030 Houston, TX, USA. ${ }^{8}$ Center for Molecular Medicine and Graduate Institute of Cancer Biology, China Medical University, Taichung, Taiwan.

Received: 24 April 2014 Accepted: 27 June 2014 Published: 23 July 2014

\section{References}

1. Li J, Gonzalez-Angulo AM, Allen PK, Yu TK, Woodward WA, Ueno NT, Lucci A, Krishnamurthy S, Gong Y, Bondy ML, Yang W, Willey JS, Cristofanilli M, Valero V, Buchholz TA: Triple-negative subtype predicts poor overall survival and high locoregional relapse in inflammatory breast cancer. Oncologist 2011, 16(12):1675-1683.

2. Meyers MO, Klauber-Demore N, Ollila DW, Amos KD, Moore DT, Drobish AA, Burrows EM, Dees EC, Carey LA: Impact of breast cancer molecular subtypes on locoregional recurrence in patients treated with neoadjuvant chemotherapy for locally advanced breast cancer. Ann Surg Oncol 2011, 18(10):2851-2857.

3. Woodward WA, Chen MS, Behbod F, Alfaro MP, Buchholz TA, Rosen JM: WNT/beta-catenin mediates radiation resistance of mouse mammary progenitor cells. Proc Natl Acad Sci U S A 2007, 104(2):618-623.

4. Phillips TM, McBride WH, Pajonk F: The response of CD24(-/low)/CD44+ breast cancer-initiating cells to radiation. J Natl Cancer Inst 2006, 98(24):1777-1785.

5. Debeb BG, Xu W, Mok H, Li L, Robertson F, Ueno NT, Reuben J, Lucci A, Cristofanilli M, Woodward WA: Differential radiosensitizing effect of valproic acid in differentiation versus self-renewal promoting culture conditions. Int J Radiat Oncol Biol Phys 2010, 76(3):889-895.

6. Van Laere S, Limame $R$, Van Marck EA, Vermeulen PB, Dirix LY: Is there a role for mammary stem cells in inflammatory breast carcinoma?: a review of evidence from cell line, animal model, and human tissue sample experiments. Cancer 2010, 116(11 Suppl):2794-2805.

7. Gong Y, Huo L, Liu P, Sneige N, Sun X, Ueno NT, Lucci A, Buchholz TA, Valero $V$, Cristofanilli M: Polycomb group protein EZH2 is frequently expressed in inflammatory breast cancer and is predictive of worse clinical outcome. Cancer 2011, 117(24):5476-5484.

8. Mu Z, Li H, Fernandez SV, Alpaugh KR, Zhang R, Cristofanilli M: EZH2 knockdown suppresses the growth and invasion of human inflammatory breast cancer cells. J Exp Clin Cancer Res 2013, 32(1):70.

9. Sparmann A, van Lohuizen M: Polycomb silencers control cell fate, development and cancer. Nat Rev Cancer 2006, 6(11):846-856.

10. Ezhkova E, Pasolli HA, Parker JS, Stokes N, Su H, Hannon G, Tarakhovsky A, Fuchs E: Ezh2 orchestrates gene expression for the stepwise differentiation of tissue-specific stem cells. Cell 2009, 136(6):1122-1135.

11. Chang CJ, Yang JY, Xia W, Chen CT, Xie X, Chao CH, Woodward WA, Hsu JM, Hortobagyi GN, Hung MC: EZH2 promotes expansion of breast tumor initiating cells through activation of RAF1-beta-catenin signaling. Cancer Cell 2011, 19(1):86-100.

12. Woodward WA, Buchholz TA: The role of locoregional therapy in inflammatory breast cancer. Semin Oncol 2008, 35(1):78-86.

13. Woodward WA, Debeb BG, Xu W, Buchholz TA: Overcoming radiation resistance in inflammatory breast cancer. Cancer 2010, 116(11 Suppl):2840-2845

14. Saigal K, Hurley J, Takita C, Reis IM, Zhao W, Rodgers SE, Wright JL: Risk factors for locoregional failure in patients with inflammatory breast cancer treated with trimodality therapy. Clin Breast Cancer 2013, 13(5):335-343

15. Dong Q, Oh JE, Chen W, Kim R, Kim RH, Shin KH, McBride WH, Park NH, Kang MK: Radioprotective effects of Bmi-1 involve epigenetic silencing of oxidase genes and enhanced DNA repair in normal human keratinocytes. J Invest Dermatol 2011, 131(6):1216-1225.

16. Alimova I, Birks DK, Harris PS, Knipstein JA, Venkataraman S, Marquez VE, Foreman NK, Vibhakar R: Inhibition of EZH2 suppresses self-renewal and induces radiation sensitivity in atypical rhabdoid teratoid tumor cells. Neuro Oncol 2013, 15(2):149-160.

17. Xia H, Yu CH, Zhang Y, Yu J, Li J, Zhang W, Zhang B, Li Y, Guo N: EZH2 silencing with RNAi enhances irradiation-induced inhibition of human lung cancer growth in vitro and in vivo. Oncol Lett 2012, 4(1):135-140.

18. Bao S, Wu Q, McLendon RE, Hao Y, Shi Q, Hjelmeland AB, Dewhirst MW, Bigner DD, Rich JN: Glioma stem cells promote radioresistance by preferential activation of the DNA damage response. Nature 2006 444(7120):756-760.

19. Diehn M, Cho RW, Lobo NA, Kalisky T, Dorie MJ, Kulp AN, Qian D, Lam JS, Ailles LE, Wong M, Joshua B, Kaplan MJ, Wapnir I, Dirbas FM, Somlo G, Garberoglio C, Paz B, Shen J, Lau SK, Quake SR, Brown JM, Weissman IL, Clarke MF: Association of reactive oxygen species levels and radioresistance in cancer stem cells. Nature 2009, 458(7239):780-783.

20. van Vlerken LE, Kiefer CM, Morehouse C, Li Y, Groves C, Wilson SD, Yao Y, Hollingsworth RE, Hurt EM: EZH2 is required for breast and pancreatic cancer stem cell maintenance and can be used as a functional cancer stem cell reporter. Stem Cells Transl Med 2013, 2(1):43-52.

21. Zeidler M, Varambally S, Cao Q, Chinnaiyan AM, Ferguson DO, Merajver SD Kleer CG: The Polycomb group protein EZH2 impairs DNA repair in breast epithelial cells. Neoplasia 2005, 7(11):1011-1019.

22. Li X, Lewis MT, Huang J, Gutierrez C, Osborne CK, Wu MF, Hilsenbeck SG, Pavlick A, Zhang X, Chamness GC, Wong H, Rosen J, Chang JC: Intrinsic resistance of tumorigenic breast cancer cells to chemotherapy. J Natl Cancer Inst 2008, 100(9):672-679.

\section{doi:10.1186/s13046-014-0058-9}

Cite this article as: Debeb et al: EZH2 expression correlates with locoregional recurrence after radiation in inflammatory breast cancer. Journal of Experimental \& Clinical Cancer Research 2014 33:58.

\section{Submit your next manuscript to BioMed Central and take full advantage of:}

- Convenient online submission

- Thorough peer review

- No space constraints or color figure charges

- Immediate publication on acceptance

- Inclusion in PubMed, CAS, Scopus and Google Scholar

- Research which is freely available for redistribution

Submit your manuscript at www.biomedcentral.com/submit
C BioMed Central 